\title{
Longitudinal variations in cross-section morphology along a glacial valley: a case-study from the Tien Shan, Ghina
}

\author{
Li Yingkui, ${ }^{1,2}$ Liu Gengnian, ${ }^{2,3}$ Cui Zhijiu ${ }^{3}$ \\ ${ }^{1}$ Institute of Geology and Geophysics, Chinese Academy of Sciences, P.O. Box 9825, Beijing 100029, China \\ ${ }^{2}$ The Key Laboratory of Water and Sediment Sciences, Ministry of Education, Beijing 100871, China \\ ${ }^{3}$ Department of Geography, Peking University, Beijing 100871, China
}

\begin{abstract}
A new model, the variable width/depth ratio (VWDR) model, is used to analyze longitudinal variations in cross-section morphology along glacial valleys. In the VWDR, the cross-sectional shape of a valley is expressed as a function of the width/depth ratio at various heights above the valley floor. Two parameters, $m$, a measure of the breadth of the valley floor, and $n$, a measure of the steepness of the valley sides, appear in the model. We have used the VWDR model to study morphological variations of crosssections along glacial valleys in the middle Tien Shan mountains, China, and find that: (1) in valleys without tributaries, $m$ increases (the valley floor becomes wider) and $n$ becomes more negative (valley sides become steeper) from the head of the valley to the equilibrium line, and then $m$ decreases and $n$ becomes less negative to the end of the valley; (2) in valleys with tributaries, a similar pattern is observed, with an oscillating maximum in $m$ and minimum in $n$ in those sections where a tributary enters the main valley. These characteristics are believed to reflect a maximization of glacial erosion potential in the vicinity of the equilibrium line and in locations of confluence.
\end{abstract}

\section{INTRODUGTION}

Glacial valleys are generally described as U-shaped in crosssection (e.g. Strahler, 1960, p. 392). The U shape is commonly cited as evidence for prior glaciation in an area and is thus useful for reconstructing paleoenvironments. A number of studies of the cross-sectional morphology of glacial valleys have been conducted in recent years. Various analytical models, including the power model $\left(y=a x^{b}\right)$ (Svensson, 1959; Graf, 1970; Doornkamp and King, 1971; Jiao, 1981; Liu, 1989; $\mathrm{Li}$ and others, 1999) and the quadratic model $\left(y=a+b x+c x^{2}\right)$ (Wheeler, 1984; Augustinus, 1992; James, 1996), have been used to describe valley cross-sections and their evolution. In addition, considerable progress has been made in analyzing the influence of glaciological (Harbor, 1992) and bedrock (Augustinus, 1992, 1995; Harbor, 1995) boundary conditions on the development of valley crossprofiles, in theoretical studies of the development of valley cross-profile morphology (Hirano and Aniya, 1988, 1989, 1990; Harbor, 1990) and in numerical simulation of valley evolution (Harbor, 1992, 1995).

Despite the frequent description of glacial valleys as U-shaped, there are many non-U-shaped glacial valleys (Doornkamp and King, 1971; Wheeler, 1984). For example, the interaction of glacial processes and patterns of rock resistance to erosion can lead to non-U-shaped glaciated valleys (Harbor, 1995). At the same time, some U-shaped valleys owe their shape to structural characteristics of the bedrock (Augustinus, 1992, 1995). These complications result in disputes about whether areas have been glaciated, especially at low altitudes (Shi and others, 1989). In order to resolve these disputes, it can be helpful to study the longitudinal variation of cross-profile morphology along valleys rather than simply exploring morphological characteristics in a single cross-section. Studies of this longitudinal variation are also helpful for exploring spatial erosion patterns of alpine glaciers.

Previous work in this field has focused on longitudinal profiles of glacial valleys (Lewis, 1947; Nye, 1952; Hooke, 1991), but, except for some qualitative observations in a few areas (Cui, 1981a; Jiao, 1981; Liu, 1989), longitudinal variations in cross-profile morphology have not received appropriate attention. In this paper, measurements of crosssections of glacial valleys in the middle Tien Shan mountains, China, are used as a basis for discussing systematic longitudinal variations in cross-profile morphology.

\section{STUDY AREAS}

The glacial valleys we studied were selected from the Bingdaban area of the Tien Shan, an area where there are U-in-U troughs (Cui, 1981a). The outer or higher troughs are believed to have formed during the Early Wangfeng Ice Age (probably oxygen isotope stage 8 (Wang, 1981a)), while the inner ones, cut into the floors of the outer troughs, formed in the Middle and Late Wangfeng Ice Ages (stages 6 and 2). The inner troughs remain relatively unmodified by subsequent processes, as landforms are modified only slowly in these high-altitude areas. Owing to their better preservation, the inner troughs are ideal for studying the morphology of glacial valley cross-sections.

The bedrock in this area is composed mainly of metamorphic rocks such as gneiss and quartz-schist, and secondarily of granitic rocks. Based on previous work (Cui, 1981a; Xiong, 1991; Cui and others, 1998) and our field investigations, the influence of lithology is reflected mainly 

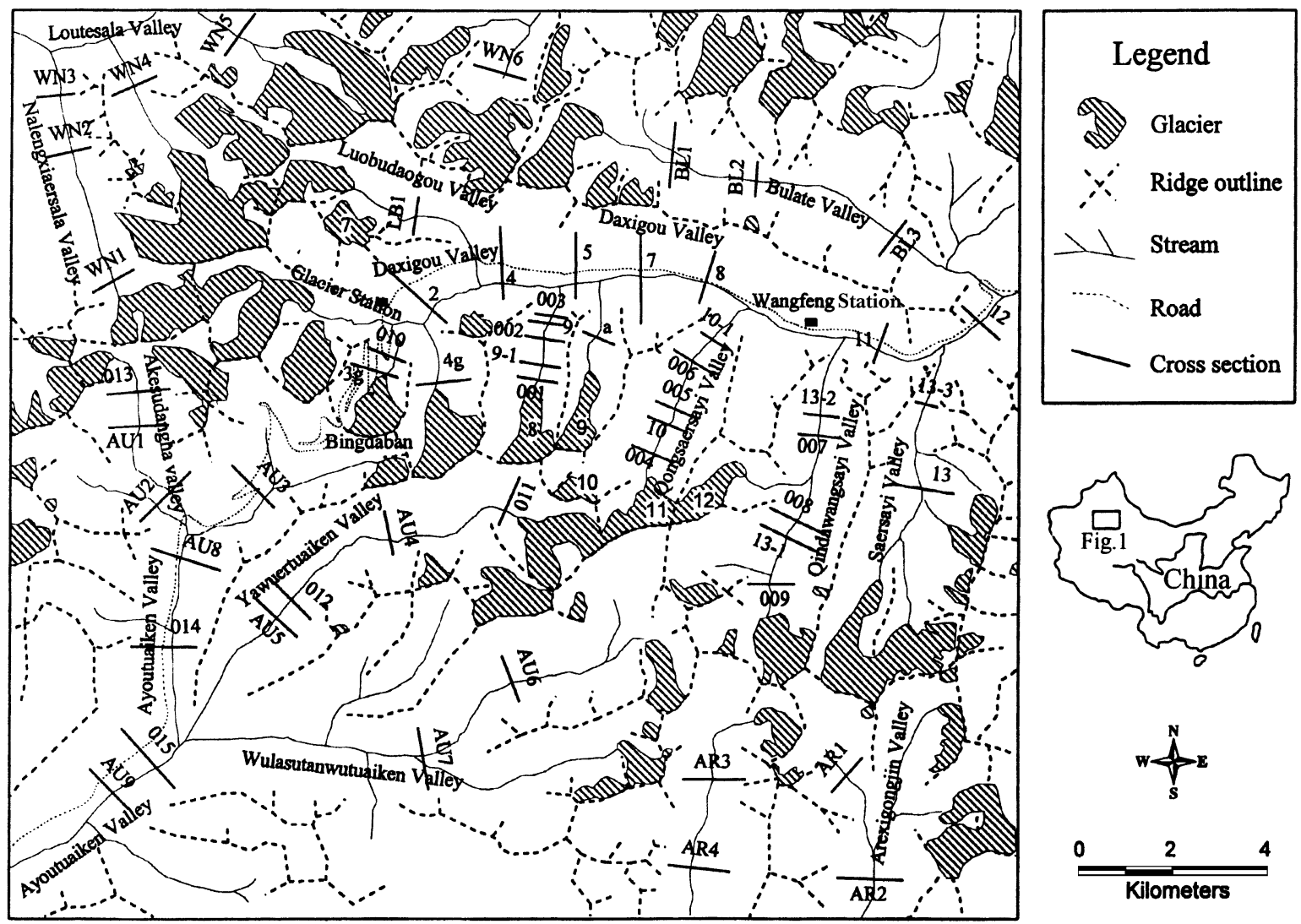

Fig. 1. Locations of cross-profiles of glacial valleys in the Bingdaban area.

in the development of micro-landforms in glacial valleys such as striae and roches moutonnées. The effect of lithology on cross-section shape is apparent only locally (Cui, 1981a). Furthermore, while the distribution and orientations of glacial valleys are controlled by the dominant structures in the area (Cui, 1981a; Wang, 1981b), these structures do not have a major influence on the shapes of valley cross-sections. In short, the dominant factor influencing cross-section shape is the capacity for glacial erosion as defined by the glacier thickness and ice flux (Wang, 1981b).

Deposits of slope debris and moraine in these glacial valleys are normally only $10-20 \mathrm{~m}$ thick, but locally, as in the vicinity of Wangfeng road maintenance station (Wangfeng station), they can be up to 40-60 m (Cui, 1981b; Cui and others, 1998). Postglacial rivers do not cut into the bedrock in most of these glacial valleys; near Wangfeng station, however, they have cut to a depth of 2-3 m.

Fifty-six cross-sections of inner troughs were sampled from 1:50000 Chinese Survey topographic maps with $20 \mathrm{~m}$ contour intervals (Fig. 1). Most of the cross-sections were located in such a way as to analyze systematic longitudinal variations in cross-profile morphology along the Glacier No. 8, Qongsaersayi, Qindawangsayi and Yawuertuaiken valleys. Ten to fifteen data points were obtained on each cross-section. Some representative cross-sections of U-shaped valleys that are approximately symmetrical are shown in Figure 2.

\section{ANALYTIGAL MODELS OF GLAGIAL VALLEY GROSS-SEGTIONS}

Two principal models have been widely used to describe the morphology of glacial valley cross-sections. The most common is the power model, first used by Svensson (1959) to describe glacial valleys in the Lapporten area, Sweden. In this model the shape of a valley is represented by

$$
y=a x^{b},
$$

where $x$ and $y$ are the horizontal and vertical distances from the lowest point of the cross-section, and $a$ and $b$ are constants which can be determined by either visual or least-squares fits on double logarithmic plots (Svensson, 1959; Graf, 1970; Doornkamp and King, 1971; Jiao, 1981; Wheeler, 1984; Hirano and Aniya, 1988; Liu, 1989; Augustinus, 1992; James, 1996; Li and others, 1999). Some of these studies have suggested that the valley morphology progressively approaches a true parabolic form with increasing glacial erosion, and that the stage of valley evolution can thus be gauged by the proximity of $b$ to 2.0 (Svensson, 1959; Graf, 1970; Jiao, 1981; Hirano and Aniya, 1988; Liu, 1989). Other studies show that boundary conditions such as bedrock erodibility and slope stability, rock mass strength and rock structure also influence $b$

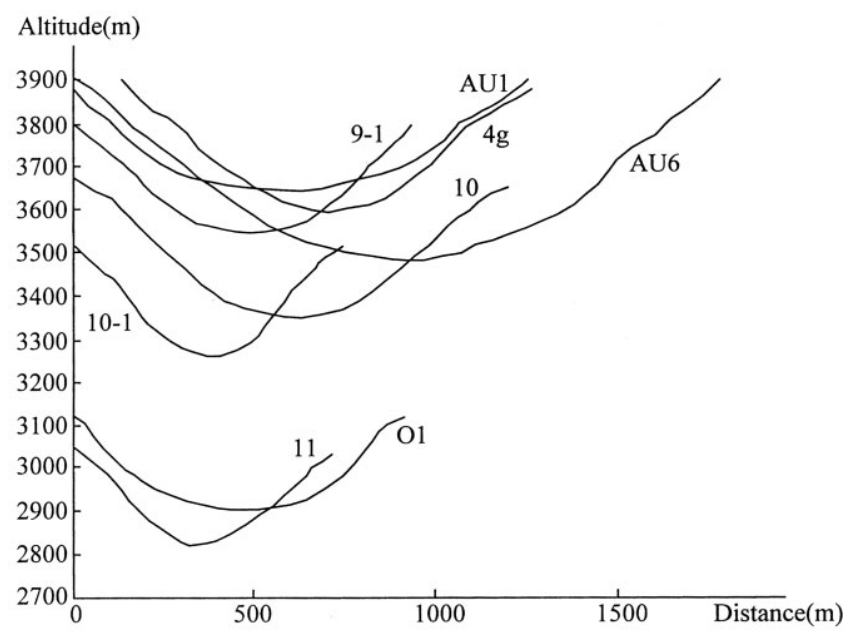

Fig. 2. Some typical cross-sections in the Bingdaban area. 
(Augustinus, 1992). Graf (1970) noted that the power model needs an additional parameter, a form ratio (depth/width) in order to describe valley morphology completely.

There are several fundamental limitations of using the power model to describe overall valley morphology. First, least-squares fits to logarithmic data are strongly influenced by local valley-bottom morphology and the selection of the origin $(x, y=0,0)$ (Wheeler, 1984; Harbor and Wheeler, 1992; James, 1996). Second, the need to locate the coordinate system precisely at the center of the valley bottom poses a problem in many valleys (James, 1996). Third, power models are sensitive to the sampling method employed; quite different results may be obtained by fitting functions to different subsets of the valley profile data (James, 1996). Fourth, power models are not appropriate for comparing cross-section morphology longitudinally along asymmetrical glacial valleys, for two reasons: (1) each cross-section must be divided into two parts with different values of $a$ and $b$, and (2) averaging the values from the two sides does not provide a mathematically consistent way of describing the overall crosssection morphology where the degree of asymmetry varies along the valley.

The second model commonly used to describe the morphology of glacial valley cross-sections is the quadratic model:

$$
y=a+b x+c x^{2}
$$

(Wheeler, 1984; Augustinus, 1992; James, 1996). Such a quadratic equation can fit a symmetrical valley cross- section completely, without the need to treat opposing valley sides separately (James, 1996). However, as with the power model, it is, for the same reasons, not appropriate for systematic comparison of cross-sections longitudinally along asymmetrical valleys.

Because neither the power nor the quadratic model is adequate for systematic theoretical analysis of longitudinal variations in asymmetric glacial valley cross-sections, a new model is needed.

\section{A NEW MODEL OF GLACIAL VALLEY GROSS- SECTION MORPHOLOGY}

\subsection{General description}

In this paper, we use a modification of the power model, which we call the variable width/depth ratio (VWDR) model, to describe the overall morphology of glacial valley cross-sections. In this model we define $G(y)$ by (Fig. 3):

$$
G(y)=\frac{w}{\left(y-y_{0}\right)}
$$

where $\left(y-y_{0}\right)$ is the height above the valley bottom, taken to be at $y=y_{0}, w$ is the width of the valley at height $y$, and $G(y)$ is the VWDR at elevation $y$. (When $y$ is the altitude of

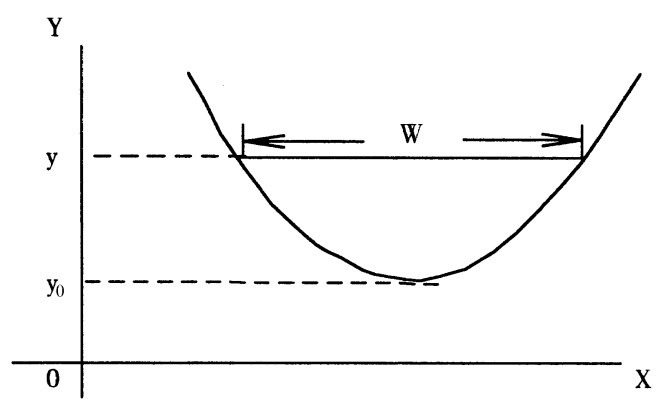

Fig. 3. Definition of parameters in the VWDR. the trimline, $G(y)$ is equal to $1 / \mathrm{FR}$, where $\mathrm{FR}$ is the form ratio defined by Graf (1970).)

In order to avoid the influence of postglacial cut or fill, the valley cross-section is smoothed before calculations are undertaken (Fig. 4). Specifically: (1) the altitude of the valley bottom is adjusted if the floor is incised by fluvial or other processes; and (2) valley-side morphology is interpolated where talus or till are present.

The adjustments are rather simple in this area because deposits on the valley floor and sides are generally $<10-20 \mathrm{~m}$ thick. Even in the vicinity of Wangfeng station, which has the thickest deposits (40-60 m), in a dataset compiled from maps with $20 \mathrm{~m}$ contour intervals only one or two points need to be adjusted. Thus, we can easily adjust these points by interpolating, by eye, using neighboring points to define the curvature of the valley side. More commonly, the problem points were removed. This did not affect the calculations noticeably. Furthermore, postglacial rivers do not cut into the bedrock in most parts of these glacial valleys. Where rivers do cut into the bedrock, near Wangfeng station (Fig. 1), the depth of incision is only $2-3 \mathrm{~m}$, which also is not enough to affect the calculations.

As with the power model, double-log plots of $G(y)$ against $\left(y-y_{0}\right)$ typically result in straight lines (Fig. 5), which thus may be described by:

$$
G=m d^{n},
$$

where $d$ is the depth $\left(y-y_{0}\right)$, and $m$ and $n$ are constants. The 56 valley cross-sections shown in Figure 1 have been fit with this model, and values of $m, n$ and the explained

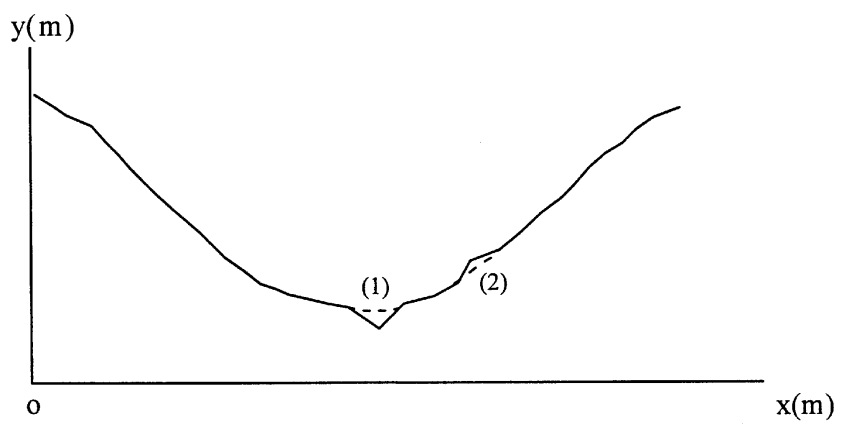

Fig. 4. Method of smoothing of valley cross-sections before calculating VWDR values: (1) interpolate across the valley bottom if the valley has been incised by fluvial or other processes in postglacial time; (2) interpolate beneath talus or moraines on valley sides.

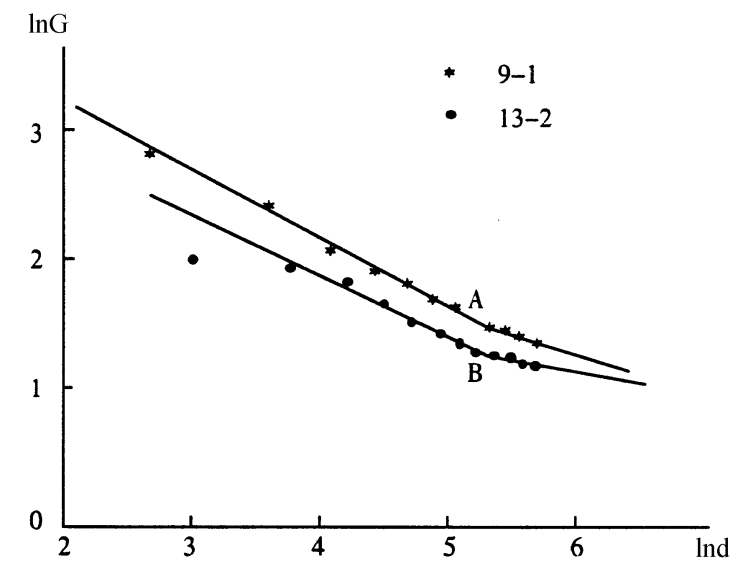

Fig. 5. Relationship between $G$ and valley depth (d). Points $A$ and $B$ are discussed in text. 
variance, $R^{2}$, calculated by least-squares techniques (Table 1). While this model, unlike the power model, incorporates data from both sides of the valley and thus can be used to describe asymmetrical valley cross-sections, it does not describe a cross-section uniquely because the horizontal (or $x$ ) coordinates of the valley sides do not appear in the equations.

To provide a physical interpretation of $m$ and $n$, replace $G$ with $w / d$ in Equation (4), thus:

$$
w=m d^{n+1} .
$$

From this it is clear that $m$ is the width of the valley when $d=$ 1 , so $m$ is a measure of the width of the valley bottom. It is also clear that $-1<n<0$. $n=-1$ describes a rectangular valley of constant width, $m$, with vertical sides. Values of $n<-1$ would describe a valley that narrows upward, which occasionally occurs but would be unrealistic in the present circumstances. $n=0$ represents the limiting case of a $\mathrm{V}$-shaped valley. Higher values of $n$ correspond to valleys with convex upward sides. Thus, as $n$ varies from -1 to 0 for a given value of $m$, valleyside slopes become progressively gentler and approach linear. Now consider the situation in which the valley cross-section is symmetrical so $w=2 x$. Then,

$$
x=(m / 2) d^{n+1}
$$

or

$$
d=(2 / m)^{1 /(n+1)} x^{1 /(n+1)} .
$$

Comparison of this with Equation (1) will demonstrate that $n=-0.5$ corresponds to the parabolic case $(b=2)$.

\subsection{Advantages and disadvantages of the VWDR model}

The VWDR model can describe the integrated morphological characteristics of entire valley cross-sections, regard- less of whether the valley is symmetrical or asymmetrical. Power functions cannot do this. Furthermore, because the $w / d$ ratio is used, the data are less sensitive to lateral positioning than is the case with power models.

The VWDR model is directly linked to the form ratio, FR, because, by definition, $G=1 / \mathrm{FR}$ at the trimline altitude. The VWDR model can also be used to estimate the location of trimlines and the value of FR even where, owing to map errors or modification by postglacial processes, the trimline is not evident on maps or in the field. To do this, we plot $\ln G$ vs $\ln d$ and seek breaks in slope. For example, in Figure 5, the points to the left of A and B are for the inner valley, and $\mathrm{A}$ and $\mathrm{B}$ represent positions of the trimline. Where the valley walls rise above the trimline, the slope of the $\ln G$ vs $\ln d$ relation decreases ( $n$ becomes less negative), and the valley begins to widen out more rapidly with increasing elevation. This is inferred to represent valley sides formed by different processes or by an earlier glaciation. At the break in slope, $G=1 / \mathrm{FR}$.

On the other hand, the VWDR model does not resolve all problems with traditional models. It, too, is sensitive to the determination of the valley-floor altitude in situations in which incision has occurred. Thus, although it can reduce problems associated with positioning in the $x$ direction, the problems in the $y$ direction still exist. Furthermore, although the VWDR model can describe the overall morphology of a valley cross-section, it loses the information on variability from the two sides, and cannot be used to generate a valley cross-section plot.

Although the VWDR model has some limitations, where valley-floor elevations are well known from previous fieldwork it can be used to compare different valley crosssections and to study longitudinal variations in cross-section morphology along a glacial valley.

\begin{tabular}{|c|c|c|c|c|c|c|c|c|c|}
\hline AU1 & -0.553 & 4.650 & 0.996 & 3800 & 10 & -0.543 & 4.303 & 0.997 & 3720 \\
\hline AU2 & -0.701 & 5.580 & 0.991 & 3760 & 13 & -0.391 & 3.620 & 0.987 & 3500 \\
\hline AU3 & -0.473 & 4.227 & 0.995 & 3800 & $13-1$ & -0.616 & 4.794 & 0.998 & 3620 \\
\hline AU4 & -0.639 & 5.075 & 0.994 & 3700 & $13-2$ & -0.387 & 3.241 & 0.961 & 3300 \\
\hline AU5 & -0.475 & 4.303 & 0.998 & 3600 & $13-3$ & -0.513 & 3.787 & 0.999 & 3160 \\
\hline AU6 & -0.465 & 4.220 & 0.999 & 3700 & 12 & -0.479 & 3.720 & 0.998 & 2920 \\
\hline AU 7 & -0.544 & 4.937 & 0.991 & 3700 & 11 & -0.371 & 3.078 & 0.997 & 3000 \\
\hline AU8 & -0.586 & 4.971 & 0.999 & 3640 & 8 & -0.489 & 4.150 & 0.998 & 3400 \\
\hline ARl & -0.490 & 3.961 & 0.994 & 3840 & 5 & -0.591 & 4.606 & 0.992 & 3440 \\
\hline $\mathrm{AR} 2$ & -0.356 & 3.736 & 0.984 & 3700 & 4 & -0.468 & 4.434 & 0.994 & 3600 \\
\hline AR 3 & -0.373 & 3.557 & 0.997 & 3800 & LB1 & -0.583 & 4.496 & 0.999 & 3800 \\
\hline $\mathrm{AR} 4$ & -0.570 & 4.752 & 0.996 & 3700 & 2 & -0.530 & 4.788 & 0.999 & 3660 \\
\hline WN1 & -0.458 & 3.859 & 0.999 & 3800 & 001 & -0.529 & 4.146 & 0.990 & 3740 \\
\hline WN2 & -0.345 & 3.394 & 0.982 & 3560 & 002 & -0.563 & 4.299 & 0.996 & 3660 \\
\hline WN3 & -0.264 & 2.642 & 0.962 & 3500 & 003 & -0.563 & 4.325 & 0.996 & 3620 \\
\hline WN4 & -0.258 & 2.891 & 0.992 & 3560 & 004 & -0.495 & 4.099 & 0.991 & 3740 \\
\hline WN6 & -0.450 & 3.946 & 0.996 & 3640 & 006 & -0.541 & 4.195 & 0.994 & 3560 \\
\hline BLl & -0.414 & 3.868 & 0.987 & 3700 & 007 & -0.407 & 3.503 & 0.997 & 3320 \\
\hline BL2 & -0.266 & 2.721 & 0.976 & 3500 & 008 & -0.520 & 4.304 & 0.998 & 3600 \\
\hline BL3 & -0.486 & 3.562 & 0.996 & 3100 & 009 & -0.415 & 3.705 & 0.990 & 3680 \\
\hline $3 \mathrm{~g}$ & -0.419 & 3.585 & 0.996 & 3840 & 010 & -0.523 & 4.192 & 0.994 & 3760 \\
\hline $4 \mathrm{~g}$ & -0.502 & 4.052 & 0.998 & 3800 & 011 & -0.365 & 3.297 & 0.997 & 3840 \\
\hline 9 & -0.598 & 4.444 & 0.999 & 3640 & 012 & -0.479 & 4.308 & 0.999 & 3640 \\
\hline $9-1$ & -0.533 & 4.157 & 0.999 & 3700 & 013 & -0.326 & 3.183 & 0.998 & 3840 \\
\hline a & -0.570 & 4.181 & 0.995 & 3700 & 014 & -0.361 & 3.737 & 0.998 & 3540 \\
\hline $10-1$ & -0.469 & 3.502 & 0.997 & 3400 & 015 & -0.505 & 4.675 & 0.998 & 3460 \\
\hline
\end{tabular}

Table 1. Statistical data on cross-sections of glacial valleys in the Tien Shan mountains

\begin{tabular}{lllllllllll}
\hline Profile No. & $n$ & $\ln m$ & $R^{2}$ & Trimline elevation & Profile No. & $n$ & $\ln m$ & $R^{2}$ & Trimline elevation
\end{tabular}




\section{LONGITUDINAL VARIATIONS IN GROSS-SEGTION SHAPE ALONG GLACIAL VALLEYS}

\subsection{Classification of glacial valleys}

To facilitate discussion, we classify glacial valleys into two basic types based on differences in map or plan form (Fig. 6):

(1) Simple valleys: A simple valley is one that has a single glacially scoured channel over most of its length. It may have more than one cirque at its head, but otherwise has no major tributaries.

(2) Compound valleys: Compound valleys are valleys with one or more major tributaries. In general, the respective channels of a compound valley may be considered to be simple valleys. Compound valleys commonly can be subdivided into three sections: (i) an upper simplevalley section, (ii) a confluent section and (iii) a lower simple section.

\subsection{Longitudinal variation in cross-section morphology along glacial valleys}

Longitudinal variations in $m, n$ and the trimline altitude along the valleys from which most of the cross-sections discussed herein were obtained are given in Figures 7 and 8. These parameters vary systematically downstream from the valley head in both simple and compound valleys.

In simple valleys, $m$ initially increases (the valley floor becomes wider) from the head of the valley, and then decreases to the valley end. Correspondingly, $n$ decreases,

(A)

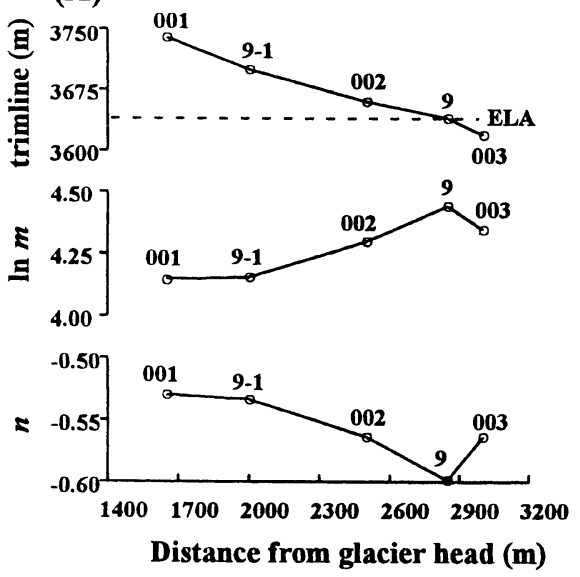

(C)
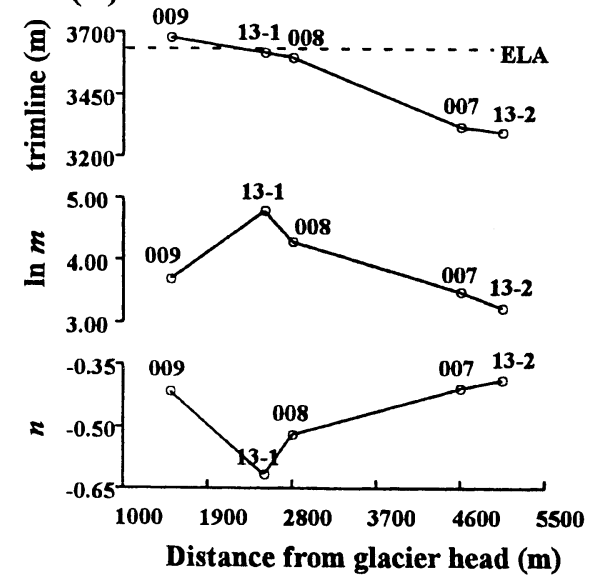
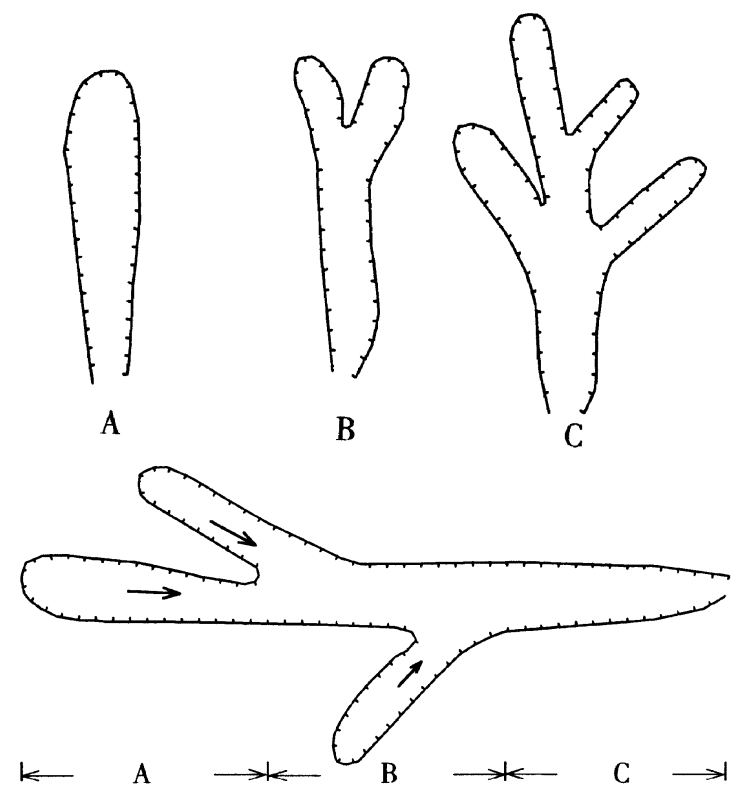

Fig. 6. Classification of glacial valleys. $A, B$, simple valleys; $C$, compound valley. (1) upper simple-valley section; (2) confluent section; (3) lower simple section.

or becomes more negative, initially (valley sides become steeper) and then increases. In compound valleys, the same pattern is observed except that $m$ and $n$ oscillate in confluent valley sections. As expected, the trimline altitude decreases with increasing distance down-valley, in both simple and compound valleys.

(B)
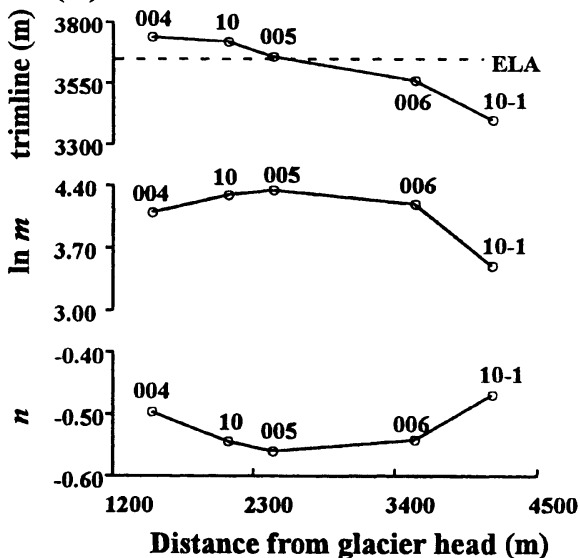

(D)
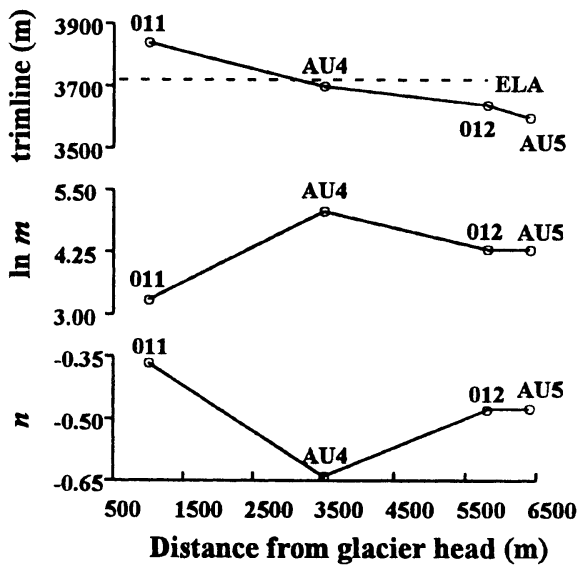

Fig. 7. Longitudinal variation of trimline altitude, $\ln m$ and $n$ along some simple valleys: (a) Glacial valley No. 8; (b) Qongsaersayi valley; (c) Qindawangsayi valley; (d) Tawuertuaiken valley. 
Table 2. Average values and standard deviations of $m$ and $n$ for simple valleys in the Tien Shan mountains

\begin{tabular}{|c|c|c|c|c|c|c|}
\hline & \multicolumn{2}{|c|}{ Above the ELA } & \multicolumn{2}{|c|}{$E L A$} & \multicolumn{2}{|c|}{ Below the ELA } \\
\hline & $n$ & $\ln m$ & $n$ & $\ln m$ & $n$ & $\ln m$ \\
\hline Areas of northward flow & $-0.484 \pm 0.055$ & $3.990 \pm 0.221$ & $-0.553 \pm 0.050$ & $4.352 \pm 0.231$ & $-0.380 \pm 0.099$ & $3.295 \pm 0.459$ \\
\hline Areas of southward flow & $-0.421 \pm 0.085$ & $3.730 \pm 0.532$ & $-0.558 \pm 0.071$ & $4.682 \pm 0.352$ & $-0.477 \pm 0.002$ & $4.306 \pm 0.003$ \\
\hline
\end{tabular}

Notes: Cross-sections above the ELA:

Areas of northward flow: 001, 004, 009, 010, WN1, WN5, BL1, 3g, 4g, 9-1, a, 10

Areas of southward flow: AU1, AR1, AR3, 011, 013.

Cross-sections near the ELA:

Areas of northward flow: 002, 003, 005, 008, 9, 13-1, WN6

Areas of southward flow: AU4, AU6, AR4.

Cross-sections below the ELA:

Areas of northward flow: 006, 007, WN2, WN3, WN4, BL2, BL3, 10-1, 13-2

Areas of southward flow: 012, AU5.

\subsection{Discussion}

Basal temperatures in alpine glaciers are likely to be at the pressure-melting point except, in some situations, for a region in the lower part of the ablation area where the glacier may be frozen to its bed (Hooke and others, 1983; Zhang and others, 1985; Cai and others, 1987). Such temperate or polythermal alpine glaciers are therefore highly erosive. Glacial valleys are one of the most important landforms produced by such glaciers. The morphological characteristics of these valleys reflect both glacial dynamics and boundary conditions such as bedrock lithology and structure (Embleton and Thornes, 1979; Augustinus, 1992, 1995; Harbor, 1995). As noted earlier, bedrock lithology and structure affect micro-landforms in the glacial valleys studied herein, but not their overall crosssectional shape. Thus, we hypothesize that the observed longitudinal variations in these glacial valleys are largely a consequence of differences in glacial dynamics, and hence erosion potential. Specifically, the wider valley floors and steeper valley walls (U shapes) indicated by higher values of $m$ and lower values of $n$ imply more glacial erosion.

The erosive potential of a temperate glacier is determined by the ice-volume flux and by the frequency and magnitude of fluctuations in basal water pressure (Embleton and Thornes, 1979; Wang, 1981b; Iverson, 1995). Frequent large water-pressure fluctuations are likely to be particularly significant where convexities in the bed cause crevassing at the surface (Hooke, 1991), but otherwise may occur anywhere along a glacial valley. Thus, they should not be expected to produce systematic down-valley changes in cross-sectional shape. The ice flux, however, reaches a maximum in the vicinity of the equilibrium line of glaciers in simple valleys. Thus, erosion is likely to be most vigorous there, resulting in broader valley bottoms and steeper valley sides.

Zhang (1981) has studied variations in equilibrium-line altitude (ELA) at the head of Ürümqi River, a north-flowing river in the Bingdaban area, using several methods. He concluded that the ELA in this area was at $3630 \pm 40 \mathrm{~m}$ during the Middle and Late Wangfeng Ice Ages, when the valleys under discussion were last modified by glacial erosion. Xiong (1991) pointed out that the ELA in the areas of southward flow is $100-150 \mathrm{~m}$ higher than in areas of northward flow in the Bingdaban area. The trimlines in Figure 7 are at or close to these elevations at cross-sections 9 (3640 m), 005 (3660 m), 13-1 (3620 m) and AU4 (3700 m) in Glacial valley No. 8 and in Qongsaersayi, Qindawangsayi and Yawuertuaiken valleys, respectively. This is consistent with the higher values of $m$ and lower values of $n$ at these

cross-sections. We can also divide the cross-sections of simple valleys into three groups, namely those above, at and below the ELA, and average the values of $m$ and $n$ in each group (Tables 2 and 3). The average values of $m$ are larger and of $n$ are more negative for the middle group.

Most of the characteristics of glaciers in compound valleys are similar to those of glaciers in simple valleys, but in compound valleys there are important interactions at glacial confluences. This is because ice flux increases more at confluences than in other areas, so the potential for erosion is larger here.

In Figure 8, locations of confluences are indicated by short vertical arrows. It will be noted that $m$ increases and $n$ becomes more negative from the upper simple-valley section to the confluent section in each of these compound valleys, reflecting the expected increase in erosion at confluences. Although the confluences are, in some cases, near the ELA (e.g. 2 and 4 in Fig. 8a), the implied increases in erosion are inferred to result primarily from increases in ice flux from the tributary valleys. Supporting this interpretation is the observation that the valleys widen appreciably below confluences, whereas simple valleys do not widen as dramatically at the ELA. The values of $m$ and $n$ appear to oscillate within the confluent section, reflecting the impact of successive confluences, while undergoing an overall decline. From the confluent section to the lower simple section, as ice flux diminishes, $m$ decreases and $n$ becomes less negative. Again, if we sort the cross-sections of compound valleys into three groups, those in upper sim-

Table 3. ANOVA ${ }^{1}$ analysis of statistical significance of $m$ and $n$ for differences between groups for simple valleys

\section{Groups}

$n$

$\ln m$

Areas of northward flow Above the ELA and ELA $P<0.05 P<0.05$ ELA and below the ELA $P<0.05 \quad P<0.05$

Areas of southward flow Above the ELA and ELA $P<0.10 \quad P<0.25$ ELA and below the ELA $P<0.35 \quad P<0.35$

Notes: $P$ : level of significance.

1 The single-factor ANOVA analysis tests the statistical significance of differences between means of different groups. The test is based on a comparison of the between-group variability (called mean-square effect, or MSeffect) with the within-group variability (called mean-square error, or Mserror). The null hypothesis is that there is no difference between the means, and the alternative hypothesis that the means are different. We compare the ratio of MSeffect and Mserror (called $F$ ) via the $F$ test. If $F$ is larger than a critical value for a certain significance level, the null hypothesis is rejected, and conversely. 
(A)
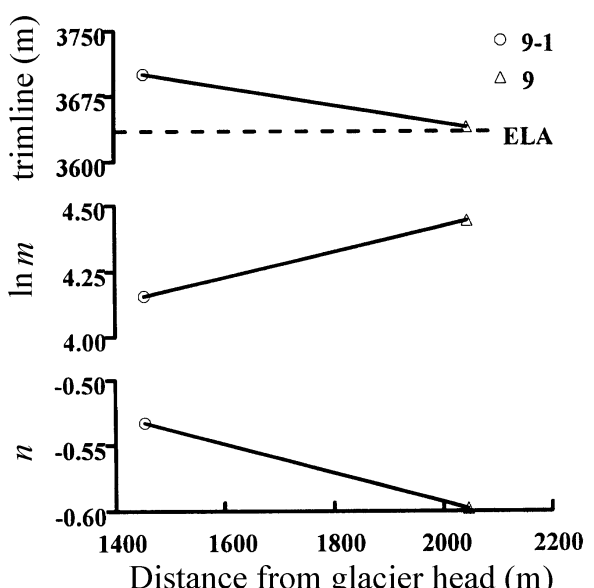

Distance from glacier head $(\mathrm{m})$

(C)

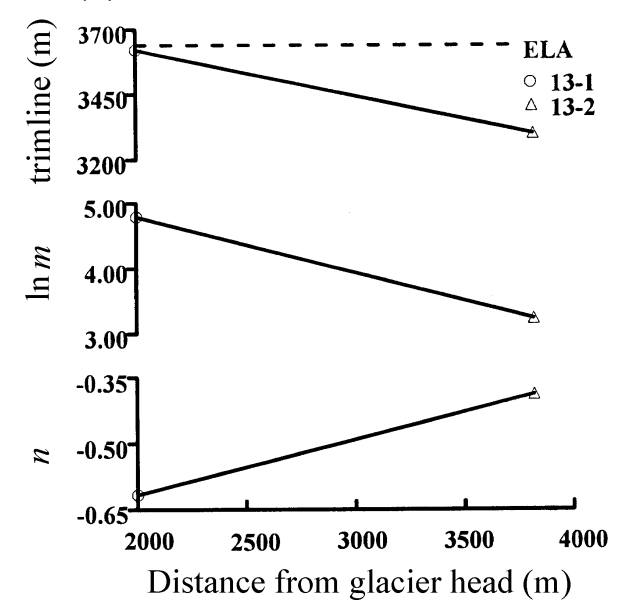

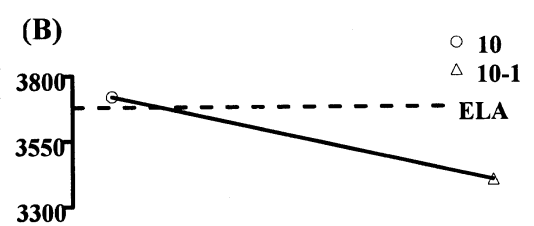
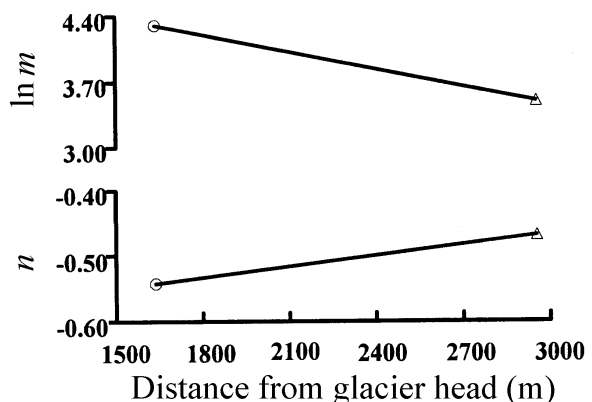

(D)

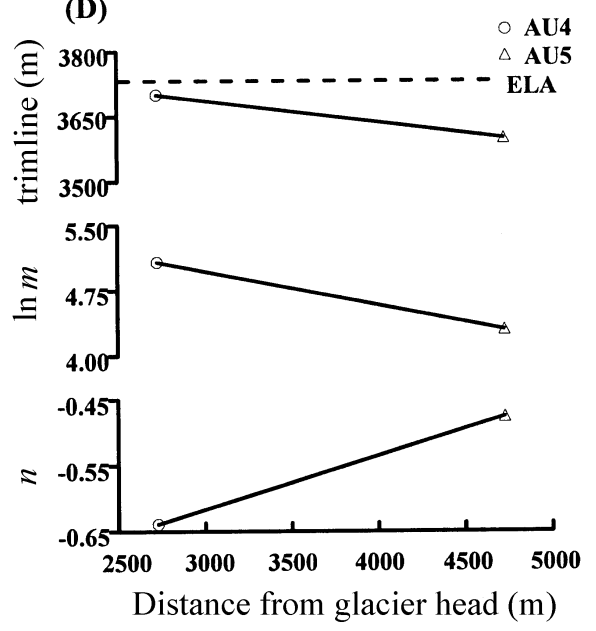

Fig. 8. Longitudinal variation of trimline altitude, $\ln m$ and $n$ along some compound valleys. The short vertical arrows in each panel show the locations of confluences. (a) Daxigou valley; (b) Glacier No. 8-Daxigou valley; (c) Akesudangha-Ayoutuaiken valley; (d) Yawuertuaiken-Ayoutuaiken valley.

ple-valley sections, those near confluences in confluent sections, and those further from confluences in confluent sections, it will be seen that the average value of $m$ is larger and of $n$ is more negative near confluences (Tables 4 and 5).

\section{GONGLUSIONS}

Longitudinal variations in cross-section morphology along glacial valleys can reflect variations in the erosive potential of the glaciers if the influence of boundary conditions such as the bedrock lithology and structure can be eliminated. These variations can be studied quantitatively by comparing successive cross-sections with the use of the VWDR model. In this model, which has some advantages over the other two commonly used ones, the power and quadratic models, the parameter $G(y)=w /\left(y-y_{0}\right)$ is plotted as a function of $d=\left(y-y_{0}\right)$. Statistical analysis reveals a power relation between $G$ and $d$ characterized by two parameters, $m$ and $n ; m$ is a measure of the breadth of the valley bottom and $n$ is a measure of the steepness of the valley sides.

With this model, we studied longitudinal variations in cross-section morphology along glacial valleys in the Bingdaban area using data from 56 cross-sections. In simple valleys, $m$ increases and $n$ becomes more negative from the head of the valley to the equilibrium line, as the valley bottom becomes broader and the sides steeper. Conversely, $m$ decreases and $n$ becomes less negative from the equi- librium line to the end of the valley, as the valley bottom narrows and the sides become gentler. In compound valleys, $m$ and $n$ follow the same pattern, except that they may oscillate through the confluent section. These variations are believed to result from longitudinal changes in glacier erosion potential along the valleys.

These conclusions are based on a field study in the middle Tien Shan mountains of China. Whether or not they are generally applicable needs further study in other areas.

\section{ACKNOWLEDGEMENTS}

We thank R. LeB. Hooke for undertaking editorial revision and text improvement, and all the members of Tien Shan Glacier Station for their help with the fieldwork. We are also deeply indebted toJ. Harbor, A. James and P. Augustinus for reviewing and providing numerous constructive criticisms and suggestions. The research was supported by the National Natural Science Foundation of China (project No. 49671075).

\section{REFERENGES}

Augustinus, P. C. 1992. The influence of rock mass strength on glacial valley cross-profile morphometry: a case study from the Southern Alps, New Zealand. Earth Surf. Processes Landforms, 17(1), 39-51.

Augustinus, P. C. 1995. Glacial valley cross-profile development: the influence of in situ rock stress and rock mass strength, with examples from the Southern Alps, New Zealand. Geomorphology, 14(2), 87-97.

Cai Baolin, Huang Maohuan and Xie Zichu. 1987. [Research on ice core 
Table 4. Average values and standard deviations of $m$ and $n$ for compound valleys in the Tien Shan mountains

\begin{tabular}{|c|c|c|c|c|c|c|}
\hline & \multicolumn{2}{|c|}{ Upper simple-valley sections } & \multicolumn{2}{|c|}{ Cross-sections near confluences } & \multicolumn{2}{|c|}{ Cross-sections further from confluences } \\
\hline & $n$ & $\ln m$ & $n$ & $\ln m$ & $n$ & $\ln m$ \\
\hline Areas of northward flow & $-0.468 \pm 0.087$ & $3.857 \pm 0.502$ & $-0.513 \pm 0.068$ & $4.289 \pm 0.430$ & $-0.445 \pm 0.046$ & $3.663 \pm 0.382$ \\
\hline Areas of southward flow & $-0.474 \pm 0.091$ & $4.131 \pm 0.517$ & $-0.562 \pm 0.079$ & $4.878 \pm 0.440$ & $-0.398 \pm 0.056$ & $4.038 \pm 0.425$ \\
\hline
\end{tabular}

Notes: Upper simple-valley sections:

Areas of northward flow: 001, 002, 003, 004, 005, 006, 007, 008, 009, 010, WN1, WN2, WN3, WN4, WN5, WN6,

BL1, BL2, BL3, 3g, 4g, 9, 9-1, a, 10, 10-1, 13-1, 13-2

Areas of southward flow: AU1, AU4, AU5, AU6, AR1, AR3, AR4, 011, $012,013$.

Cross-sections near confluences:

Areas of northward flow: 13, 13-3, 5, 4, LBl, 2

Areas of southward flow: AU2, AU3, AU7, AU8, 015.

Cross-sections further from confluences:

Areas of northward flow: $12,11,7,8$

Areas of southward flow: AU9, AR2, 014.

Table 5. ANOVA analysis of statistical significance of $m$ and $n$ for differences between groups for compound valleys

\begin{tabular}{|c|c|c|c|}
\hline & Groups & $n$ & $\ln m$ \\
\hline \multirow[t]{2}{*}{ Areas of northward flow } & Upper simple-valley sections and sections near confluences & $P<0.35$ & $P<0.10$ \\
\hline & Sections near and further from confluences & $P<0.20$ & $P<0.10$ \\
\hline \multirow[t]{2}{*}{ Areas of southward flow } & Upper simple-valley sections and sections near confluences & $P<0.15$ & $P<0.05$ \\
\hline & Sections near and further from confluences & $P<0.05$ & $P<0.10$ \\
\hline
\end{tabular}

Notes: $P$ : level of significance.

temperature of Glacier No. 1 in the Ürümqi river headwaters.] Chin. Sci. Bull., 32(22), 1732-1733. [In Chinese.]

Cui Zhijiu. 1981a. [Glacial erosion landforms and development of trough at the head of Ürümqi river, Tian Shan.] f. Glaciol. Cryopedol., 3, Special Issue, 1-15. [In Chinese with English summary.]

Cui Zhijiu. 1981b. [Kinds and features of glacial moraine and till at the head of Ürümqi river, Tian Shan.] F. Glaciol. Cryopedol., 3, Special Issue, 36-48. [In Chinese with English summary.]

Cui Zhijiu, Xiong Heigang and Liu Gengnian. 1998. [Landform processes and sediment features of cryosphere in the Tienshan Mountains, China.] Shijiazhuang, Hebei Science and Technology Press. [In Chinese.]

Doornkamp, J. C. and C. A. M. King. 1971. Numerical analysis in geomorphology. London, Arnold.

Embleton, C. and J. Thornes. 1979. Process in geomorphology. London, Edward Arnold.

Graf, W. L. 1970. The geomorphology of the glacial valley cross section. Arct. Alp. Res., 2(4), 303-312.

Harbor, J. M. 1990. A discussion of Hirano and Aniya’s $(1988,1989)$ explanation of glacial-valley cross profile development. Earth Surf. Processes Landforms, $15(4), 369-377$.

Harbor, J. M. 1992. Numerical modeling of the development of U-shaped valleys by glacial erosion. Geol. Soc. Am. Bull., 104(10), 1364-1375.

Harbor, J. M. 1995. Development of glacial-valley cross sections under conditions of spatially variable resistance to erosion. Geomorphology, 14(2), 99-107.

Harbor, J. M. and D. A. Wheeler, 1992. On the mathematical description of glaciated valley cross sections under conditions of spatially variable resistance to erosion. Earth Sur. Processes Landforms, 17 (5), 477-485.

Hirano, M. and M. Aniya. 1988. A rational explanation of cross-profile morphology for glacial valleys and of glacial valley development. Earth Surf. Processes Landforms, 13(8), 707-716.

Hirano, M. and M. Aniya. 1989. A rational explanation of cross-profile morphology for glacial valleys and of glacial valley development: a further note. Earth Surf. Processes Landforms, 14(2), 173-174.

Hirano, M. and M. Aniya. 1990. A reply to "A discussion of Hirano and Aniya's $(1988,1989)$ explanation of glacial-valley cross-profile development" by Jonathan M. Harbor. Earth Surf. Processes Landforms, 15 (4), 379-381.

Hooke, R. LeB. 1991. Positive feedbacks associated with erosion of glacial cirques and overdeepenings. Geol. Soc. Am. Bull., 103(8), 1104-1108.

Hooke, R. LeB., J. E. Gould and J. Brzozowski. 1983. Near-surface temperatures near and below the equilibrium line on polar and subpolar glaciers.
Z. Gletscherkd. Glazialgeol., 19(1), 1-25.

Iverson, N. R. 1995. Processes of erosion. In Menzies, J., ed. Modern glacial environments: processes, dynamics and sediments. Vol. 1. Glacial environments. Oxford, etc., Butterworth-Heinemann, 241-259.

James, L. A. 1996. Polynomial and power functions for glacial valley crosssection morphology. Earth Surf. Processes Landforms, 21 (5), 413-432.

Jiao Keqin. 1981. [Cross-section of glacial valley at the head of Ürümqi river, Tian Shan.] 7. Glaciol. Cryopedol., 3, Special Issue, 92-96. [In Chinese with English summary.]

Lewis, W.V. 1947. Valley steps and glacial valley erosion. Inst. Br. Geogr. Trans., $13,19-44$.

Liu Gengnian. 1989. [Research on glacial erosional landforms: case study of Luojishan Mt, western Sichuan.] F. Glaciol. Geocryol., 11 (3), 249-259. [In Chinese with English summary.]

Li Yingkui, Liu Gengnian and Cui Zhijiu. 1999. [The morphological character and paleo-climate indication of the cross section of glacial valleys.] [7. Basic Sci. Eng.], 7 (2), 163-170. [In Chinese.]

Nye, J. F. 1952. The mechanics of glacier flow. F. Glaciol., 2(12), 82-93.

Shi Yafeng, Cui Zhijiu and Li Jijun. 1989. [Quaternary glacier and environment issues in eastern China.] Beijing, Science Press. [In Chinese.]

Strahler, A. N. 1960. Physical geography. Second edition. New York, John Wiley.

Svensson, H. 1959. Is the cross-section of a glacial valley a parabola? F. Glaciol., 3(25), 362-363.

Wang Jingtai. 198la. [Ancient glaciers at the head of Ürümqi river, Tian Shan.] f. Glaciol. Cryopedol., 3, Special Issue, 57-67. [In Chinese with English summary.]

Wang Jingtai. 1981b. [On the mechanism of formation of glacier erosion topography at the source region of Ürümqi river, Tian Shan.] F. Glaciol. Cryopedol., 3, Special Issue, 16-23. [In Chinese with English summary.]

Wheeler, D.A. 1984. Using parabolas to describe the cross-sections of glaciated valleys. Earth Surf. Processes Landforms, 9(4), 391-394.

Xiong Heigang. 1991. [The comparative research of till with debris flow deposits and glacial geomorphic process of Tian Shan Mt.] (Ph.D. thesis, Peking University.) [In Chinese.]

Zhang Xiangsong, Zhu Guocai, Qian Songlin, Chen Jiyang and Shen Ying. 1985. [Radar measuring ice thickness of No. 1 Glacier at the source of Ürümqi River, Tien Shan.] f. Glaciol. Geocryol., 7(2), 153-162. [In Chinese with English summary.]

Zhang Zhenshuan. 1981. [Changes of snowline at the head of Ürümqi river, Tian Shan.] 7. Glaciol. Cryopedol., 3, Special Issue, 106-113. [In Chinese with English summary.] 